\title{
Optimization design of downsize engine structure based on dynamic knock excitation
}

\author{
Yang Bo ${ }^{1,}$, Wang Wenrui ${ }^{1, b}$ and Li Zhiyong ${ }^{1, c}$ \\ ${ }^{1}$ University of Science and Technology Beijing, China \\ ayangbo201701@163.com, bgmbitwrw@ustb.edu.cn, ${ }^{c} 1146811838 @ q q . c o m$
}

Keywords: Downsize engine, Knock excitation, Stress distribution, Fatigue life.

Abstract. The small size of the city vehicle gasoline engine is the key point of the current energy saving and emission reduction. The application of multi stage turbocharger technology has become a research hotspot, which leads to a higher compression ratio, the average effective pressure in the combustion chamber is further increased, and the engine knock phenomenon is frequent. In this paper, based on the measurement of the pressure in the cylinder of the gas suction, the influence of the knock excitation on the strength of the piston is studied, pressure of the detonation is taken as the dynamic excitation of the piston, and the stress distribution under the dynamic excitation is studied. Then simulate the actual working conditions of the engine by changing the maximum value of cylinder pressure.

\section{Introduction}

The improvement of energy efficiency and exhaust emissions of automotive vehicles has been become more attractive in automotive industry, as a result of the increasing in the awareness to global environmental issue. Engine downsize is one of the effective solutions to achieve the above target. The downsized gasoline engine will have a smaller chamber and thus the amount of exhaust gas is also reduced. However, engine knock is one of the limitations of downsized engine. It occurs more often within downsized engine ${ }^{[1]}$.

Nowadays, spark-ignition engine downsizing appears as a major way to improve fuel consumption and reduce exhaust emission, which is the trend of engine design under the more and more stringent environmental requirements ${ }^{[2]}$. However, engine downsizing leads to the higher cylinder pressure, temperature and power density, which have been demonstrated to be easier to cause knocking combustion $^{[3]}$.

\section{Experimental study on downsize engine knock excitation}

Experimental measurement of internal pressure of detonation excitation.

The most commonly used method for the detection of cylinder pressure is the pressure sensor, which is affixed to the top of the cylinder to extract the cylinder pressure signal. But due to its use of a piezoelectric crystal as the measuring element, the output signal is weak, need to charge amplifier is connected in series with, and are connected with a rotary encoder, followed by continuous capture 50 cycles of engine cylinder pressure change value, knock excitation signal, as Fig lindicates:

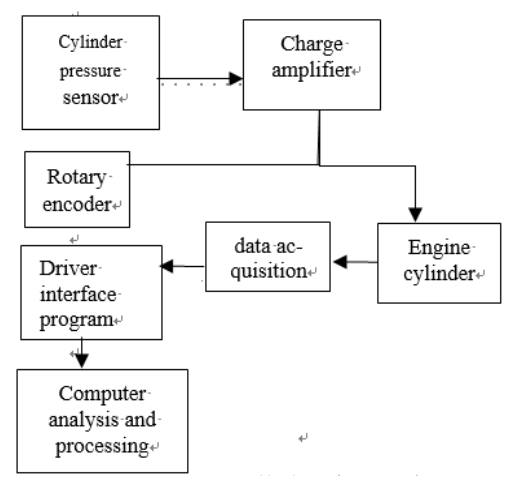

Fig1: Detonation excitation pressure measurement 
Knock excitation characteristic description

Fig 1 indicates the experimental cylinder pressure curve of a naturally aspirated engine at 1500 rpm for one complete engine cycle. The peak cylinder pressure is approximately 45 bar.
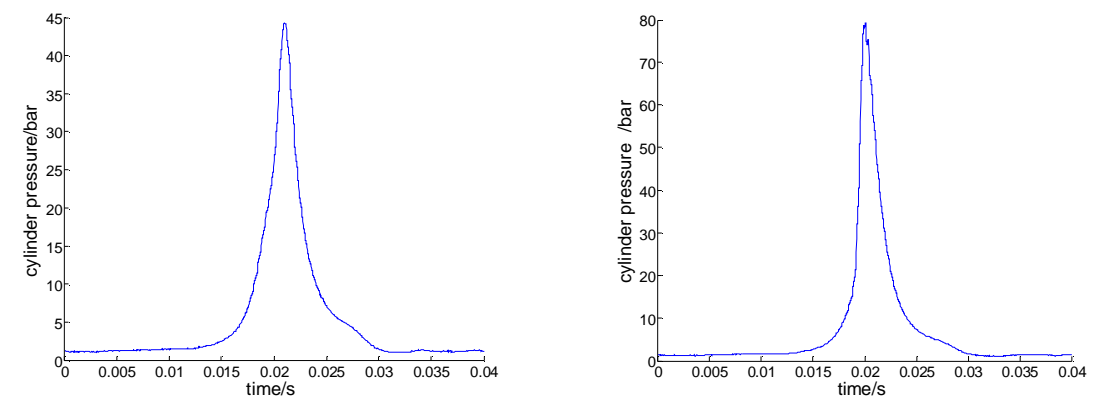

Fig2. One cycle pressure curve in the cylinder Fig3. One cycle pressure curve in EGR cylinder The peak cylinder pressure can reaches up to 100 bars while EGR is applied to the engine, the cylinder pressure curve is shown in Figure 2. While engine knock occurs, the peak cylinder pressure is increased to 180 bars and the pressure variation is indicated in Figure 3.

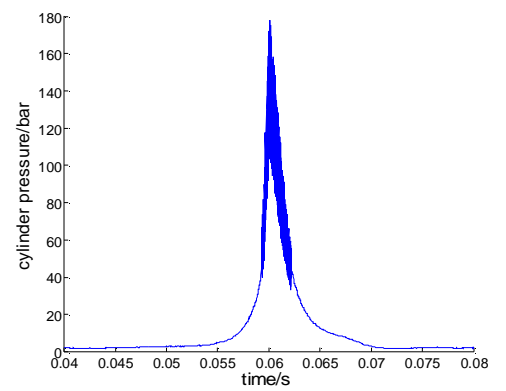

Fig4: One cycle of EGR cylinder pressure curve

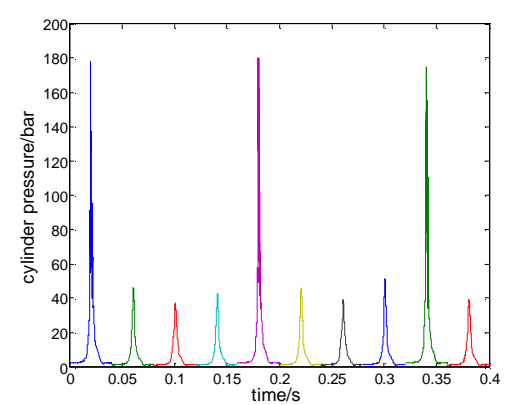

Fig5.Interval3 cylinder pressure curve

Downsized engine has a higher pressure compensation which leads to change in the pressure variation curves. The pressure curves is now either a combination of a higher value and 3 lower value in one complete engine cycle, as Figure 5 indicates.

\section{Dynamic strength finite element model of dynamic knock excitation}

Finite element model of piston fatigue strength

The piston model is implemented based on a Rover K16 four strokes gasoline engine with a cylinder volume of $1397 \mathrm{~m}^{3}$ and stroke length of $79 \mathrm{~mm}$. The applied constraints and load on this piston model is made close to reality. Tetrahedrons mesh generation method is used to produce the finite element model mesh plot. Table 1 shows the piston model and Fig7 shows piston model:

Table 1: Basic parameters of the piston

\begin{tabular}{ll}
\hline parameters & values \\
\hline outer diameter of piston & $37.5 \mathrm{~mm}$ \\
piston height & $66.1 \mathrm{~mm}$ \\
poisson ratio & 0.3 \\
elastic modulus & $7100 \mathrm{MPa}$ \\
material density & $2770 \mathrm{~kg} / \mathrm{m} 3$ \\
thermal expansion coefficient & $2.3 \times 10-5 /{ }^{\circ} \mathrm{C}$ \\
piston material & Aluminum \\
piston pin material & construction steel \\
\hline
\end{tabular}

In terms of exposure configuration, the piston rod is ignored; the interaction between the piston rod and pin is replaced by a displacement constraint in Y-axis direction. The contact between the inner wall surface of pin hole and it is set to rough contact and interaction forces. As Fig8 shows.

In order to calculating the applied load, there are two steps: 1) the temperature at the top of piston is set to $310^{\circ} \mathrm{C}$ and the bottom is set to $110^{\circ} \mathrm{C}$. 2) Knock excitation is applied. 

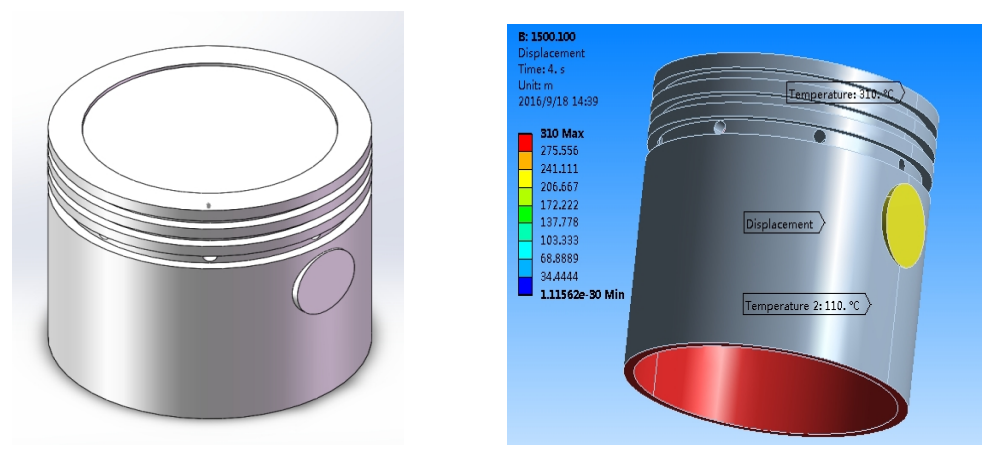

Fig6.Three-dimensional model of piston components

Model validation

Fig 8 shows the simulation results while temperature load is applied. These values are determined by measuring the piston parts temperature, looking literatures and applying semi-empirical equations ${ }^{[5]}$.The temperature distribution is agreed with $\operatorname{Ref}^{[4]}$.

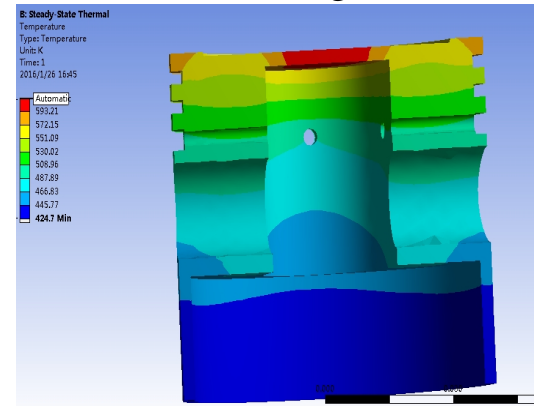

Fig8: Piston temperature field in standard condition

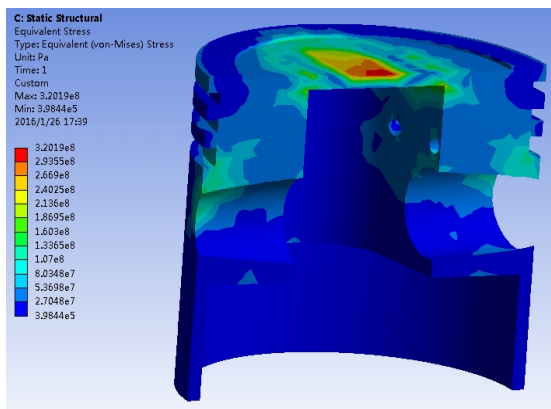

Fig9: Piston coupled stress distribution

The maximum cylinder pressure is approximately $8.5 \mathrm{MPa}$ under engine calibration conditions. This pressure is applied on top of the piston and acting as an incentive force. As Fig 9 shows. From the simulation results, it can be seen that the maximum stress and strain is at the top of piston and it is agreed with $\operatorname{Ref}^{[5]}$. Therefore, the developed model is close to reality and is relatively accurate.

\section{Dynamic intensity distribution of dynamic knock excitation and structure optimization}

Study on pressure excitation under different working conditions

The pressure signal is collected by the experiment. After the data is processed by MATLAB, the basic parameters of pressure signal in different working conditions are obtained, as Table 3 indicates:

Table 3: Basic parameters of pressure excitation signals under different working conditions

\begin{tabular}{cccc}
\hline $\begin{array}{c}\text { speed } \\
(\mathrm{r} / \mathrm{min})\end{array}$ & $\begin{array}{c}\text { pressure amplitude } \\
\text { and form (bar) }\end{array}$ & $\begin{array}{c}\text { Mean value of } \\
\text { pressure signal } \\
(\text { bar })\end{array}$ & $\begin{array}{c}\text { maximum } \\
\text { pressure signal } \\
(\text { bar })\end{array}$ \\
\hline \multirow{2}{*}{1500} & 40 & 40.3 & 51.7 \\
& 100 & 97.4 & 30.38 \\
\hline
\end{tabular}

The study of the dynamic stress distribution under different knock working conditions

When the speed is $1500 \mathrm{r} / \mathrm{min}$, the $40 \mathrm{bar}$, 100bar and interval 3 pressure are applied to the maximum stress at the top of the piston, and the stress distribution are showed in Fig10(a)-(d):

Comparison of stress and cause analysis under different working conditions

It can be seen from the results of the finite element calculation

1) Due to the smaller thickness of the piston top, the maximum stress part is at the top of the piston and the top of piston pin hole.

2) Compared to the $1500 \mathrm{r} / \mathrm{min}$ speed under the conditions of the stress, the shape of the curve is generally similar to the load, the trend is similar, as Fig10 (e) shows: 


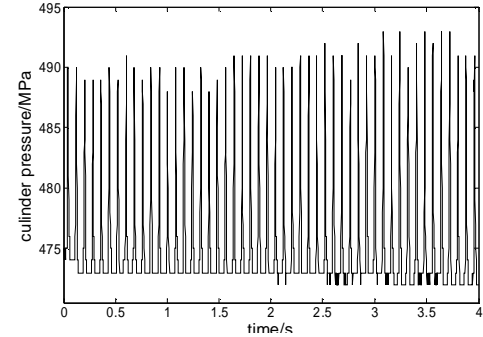

(a)

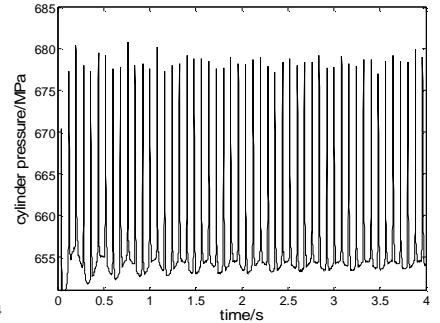

(b)

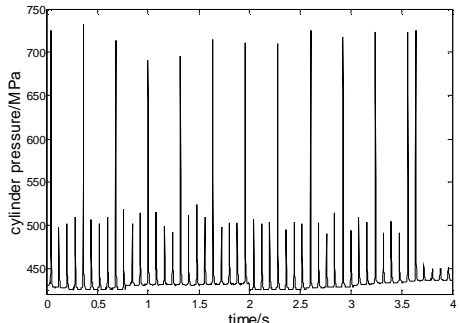

(c)

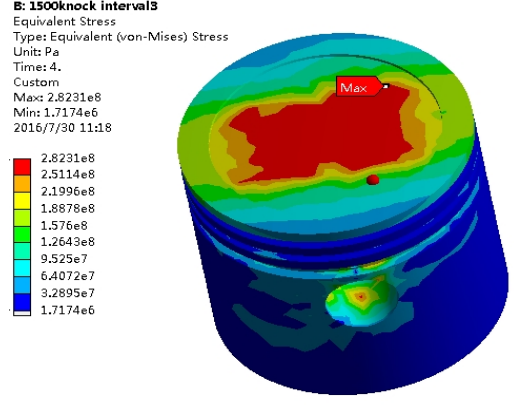

(d)

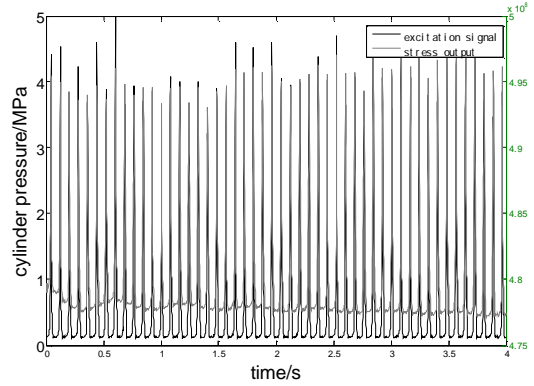

(e)

Optimum design of piston structure

Fig10. Dynamic excitation curve and stress curve

The shape, position and size of the piston are related to the concrete form of the combustion chamber, and the piston can be divided into 3 types, such as flat top piston, convex top piston and concave piston.

Flat topped piston is a plane, the utility model has the advantages of is a small heat absorption area. simple manufacturing process, small heating area and stress at the top of the distribution is more uniform $^{[6]}$; convex head at the top of the piston is raised with a dome, at the top of the high strength, plays a role of guidance, to improve the process of exchanging the gas ${ }^{[7]}$, as Fig11 shows:

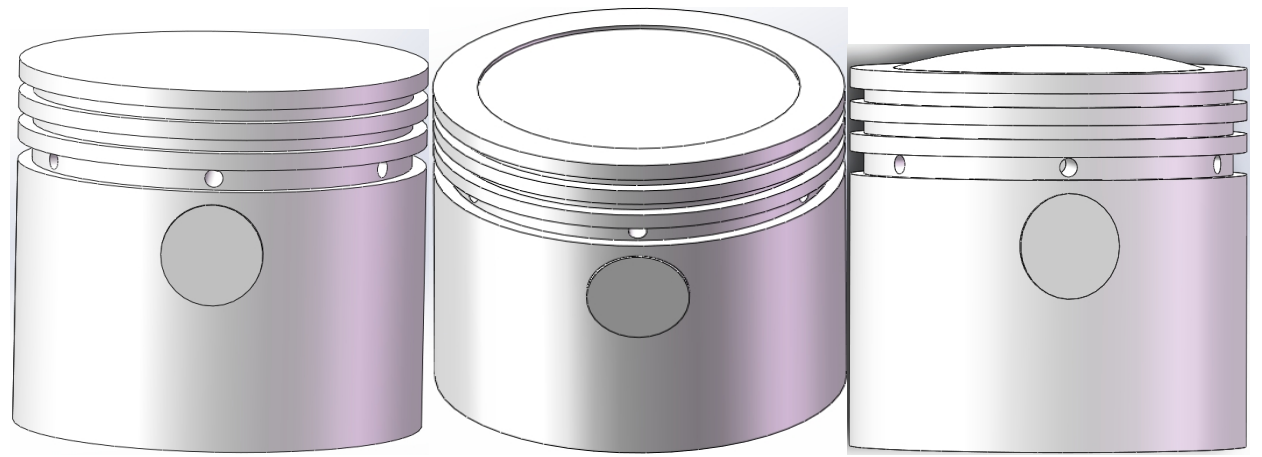

Fig11. Three different styles of piston

The Ncode-designlife processing software to predict the fatigue life of the piston and the model input module that piston thermal coupling the outcome document of the rst imported Design Life, interval3 life contour results are as follows:

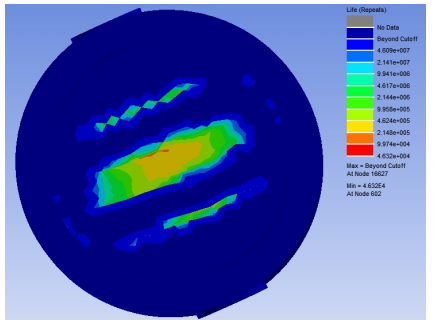

Fig12. Fatigue results of concave top piston

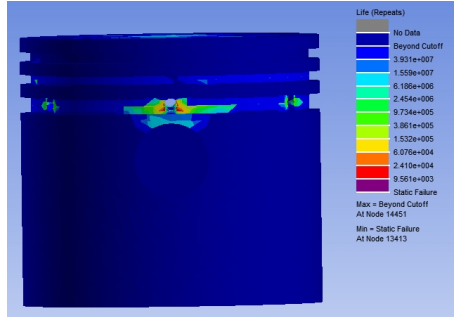

Fig13. Fatigue results of flat top piston

The top structure is changed into convex shape, and the fatigue life is calculated as follows:

Through the two group, we found that the oil hole in the upper part of the piston pin is in the stress concentration phenomenon, and the fatigue life is minimum. If the oil hole is removed, the following fatigue calculation results are shown below: 


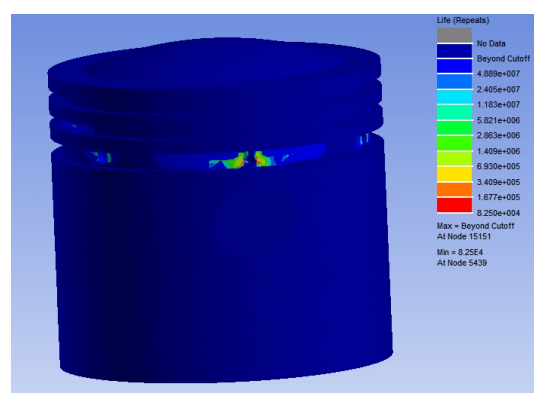

Fig14. Results of convex top piston

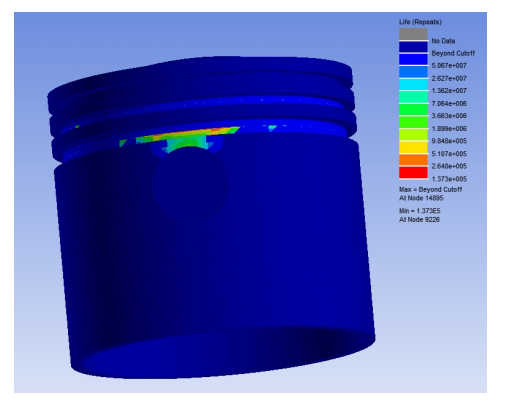

Fig15: results of convex top piston without oil hole

The results showed that flat roofed structure of the minimum cycle times at least, 9.6Error! Reference source not found. $10^{3}$, concave roof structure for 4.6 Error! Reference source not found. $10^{4}$ times, bald structure cycle maximum number is 8.3 Error! Reference source not found. $10^{4}$ times, after removing the oil hole, cycles increases to 1.4Error! Reference source not found. $10^{5}$ times, to achieve the purpose of optimization.

\section{Conclusions}

1) Engine miniaturization, using multilevel pressure as the pressure compensation, due to the improvement of power per liter in cylinder compression ratio, the end of the mixture will be more easy self-ignition and combustion, normal combustion and shock wave produced by the shock wave interaction caused by detonation, mechanical damage, and even irreversible damage to parts of the piston and cylinder;

2) In the cylinder maximum stress curve and the knock excitation curves in the trend curve is basically the same, in the same time presents the rise and fall of the trend are in one-to-one correspondence with the same, and should force curve of maximum value and minimum value of the moment corresponding to the knock and incentive the value time agreement.

3) Change the piston top structure and the structure of the piston, the piston can bear greater pressure, and remove the oil hole, the stress concentration phenomenon will disappear, the number of working cycle will increase.

\section{Acknowledgements}

This work was financially supported by the Central Universities Foundation (FRF-TP-15-023A3),

\section{References}

[1] WANG Zhi; Long Yan; Wang Jianxin. Research progress of pre-ignition and super-knock in boost gasoline engine [J]. Automotive Safety and Energy, 2015, 6(1):p.17-19 .

[2] Xu Shaogong, Qin Meijian, Li Lulu. Research on gasoline engine knock. Equipment Manufacturing Technology. 2014, 9:p.186-188 .

[3] Fan Mingqiang. Miniaturization of engine is an effective way to energy saving and emission reduction [J].Master the Basic, 2015, 10:100-106 .

[4] Zhang Junhui , Li Zhigang, Wang Tiening. Retrospect Status and Expectation for Turbocharger Technology of Vehicle. SMALL INTERNAL COMBUSTION ENGINE AND MOTORCYCLE, 2007, 36(1):p.66-69 .

[5] Tian Cheng. Thermal mechanical coupling analysis and fatigue life prediction of CNG type YC6MK375N-30 engine piston.Wu Han : Wu Han Li Gong University, 2013:p.23-40 .

[6] John H.S.Lee.The Detonation Phenomenon.National Defense Industry Press, 2013:p.202-203. 
[7] Yao Chunde, Yao Anren,Xu Han.Mechanism of Components Damaged by Internal Combustion Engine Knocking[M]. Science Press, 2015:p.33-40. 